\title{
Pathology of IT Projects Implementation in Iranian Organizations
}

\author{
Kamran Mohamadkhani \\ Department of Higher Education Administration, School of Management and \\ Economics, Science and Research Branch, Islamic Azad University (IAU), Tehran, Iran \\ E-mail: k.kamran@srbiau.ac.ir
}

Ebrahim Nazari Farokhi

Department of Information Technology Management, School of Management and Economics, Science and Research Branch, Islamic Azad University (IAU), Tehran, Iran E-mail: E60_itmgtn@yahoo.com

\section{Mohammad Nazari Farokhi}

Department of Computer Enginniering, Science and Research Branch, Islamic Azad University (IAU), Khorramabad, Iran

E-mail: M_kasitman@yahoo.com

Received: April 25, 2013 Accepted: May 15, 2013 Published: June 26, 2013

doi:10.5296/bms.v4i1.3917 URL: http://dx.doi.org/10.5296/bms.v4i1.3917

\begin{abstract}
Such capabilities as strengthening the relationship at any time and place, saving large amounts of information in a small space, and accessible, high-volume and high-speed numerical processing of data and providing the organizations with quick, accurate, and inexpensive communication stand among IT capabilities in the information age. Concentrating on the important role of information technology has encouraged managers in charge of organizational decision making to use IT capabilities to create a competitive advantage in their organizations. In this paper, identification and prioritization of factors affecting IT implementation projects in Iranian organizations was scrutinized. Research method in terms of data type was quantitative and as far the purpose of the study concerns, this research falls within the category of applied studies. The main question of the paper was what were the main reasons for the failure of IT
\end{abstract}




\section{Macrothink}

Business Management and Strategy

ISSN 2157-6068

projects implementation in organizations today? Through a vast review of literature, effective Indicators of the implementation of IT projects in various organizations around the world were identified and after primary screening by distribution of initial questionnaire and statistical analysis followed, 7 effective Indicators for implementation of IT projects in Iranian organizations were identified and prioritized through DEMATEL method.

Keywords: Pathology, Information Technology, Infrastructure, Group Decision Making, Effective Indicators, DEMATEL ${ }^{1}$.

\footnotetext{
${ }^{1}$ Decision Making Trial and Evaluation Laboratory
} 


\section{Introduction}

Today the world is moving faster and faster. Decisions must be made quickly and the pace of activities to remain competitive (Huber, 2004). The importance of technology in both manufacturing and services sector is growing. New and advanced technologies are made situated for products, selective services, and high quality. So technology can strengthen competitive forces. Many technologies, Encompassed a wide area of business. However, perhaps the most effective technology is web-based information technology (Motiwalla and Hashemi, 2003).

In fact, IT has created a great development in the business activities that facilitate the move toward digital economy (Turban, et al, 2006).

Information Technology has been defined in various ways by different authors. Over the years, IT has been conceptualized and measured differently by different researchers. The majority of the authors, however, parallel Information Technology with computer systems. Whisler (1970), for instance, defines IT as "The computer based technology of sensing, coding, transmitting, translating and transforming information".

Robey (1977) describes IT as "The installation of computer based information systems". Cash et al.(1983) wider IT scope and define Information Technology as "The integration of, data processing, telecommunications and office automation".

Buchanan and Boddy (1983) define IT as "All technology dealing with computer aided manufacturing and computer aided administration". According to Reynold (1995) "IT is any computer based system used in transferring of information from one person to another person or group of persons who requires that information for diversified activities". Mehta and Shah (1998) define IT as "Information Technology is a combination of technologies as computer networks, imaging technology, massive data storage and artificial intelligence”. Long and Long (1999) have tried to link all above definitions and give definition of IT in this way that "IT is a collective reference to the integration of computing technology and information processing. Any form of computer based system that has the capability of collecting, processing, and outputting information is called Information Technology". According to another definition "IT means the use of hardware, software services and supporting infrastructure for management of delivering information. IT is using the hardware and software used to store, retrieve, process and transmit data."(Laudon and Laudon, 1998).

Gupta (2000) narrates that "IT includes hardware, software, databases, networks, and other related components which are used to build information systems" Kendall \& Kendall (2000) also comes up with the same idea and say that "IT is the technology that supports activities involving the creations, storage, manipulation and communication of information together with their related methods and management applications".

William and Sawyar (2005) define IT as a general term that describes any technology that help to produce, manipulate, process, store, communicate, and/or disseminate information. This definition may be regarded as the comprehensive definition, as it covers all aspects discussed by different researchers above and includes all the components and processes 
needed to carry out information processing work in the organization.

It can be summarized from above definitions that IT concept came from a merging of computer with telecommunications technologies. Many researchers have defined Information Technology as a term that encompasses all forms of technology utilized to create, capture, manipulate, communicate, exchange, present, and use information in its various forms (business data, voice conversation, still image, motion pictures, multimedia presentation, another forms, including those yet not conceived (Poku \& Vlosky, 2002).

Information System Management is another term, which is used synonymously for Information Technology and these two terms have become so linked to each other that they are often used interchangeably (Shelly et. al, 2004). Oliner and Sichel (2000) also argued that the terms 'Information System' and 'Information Technology' have become so interrelated that they are often used in substitute to each other.

Information Technology also creates a serious dilemma for management today. IT innovations have the potential for changing the competitive game for any organization. On the other hand, the size of IT investments put increasing pressure on managers to assess its business value. One key to this dilemma is to improve the ability to measure and track the impact of IT on productivity. Alongside, the seemingly inexorable rise in IT investment in the last 20 years, there have been considerable uncertainty and concern about the productivity and efficiency impact of IT being experienced in work organization. However, in quest of improving efficiency and effectiveness, the companies are making heavy investments in IT. These enduring magnitudes of investment in IT have drawn attention of many researchers, managers and policy makers to the impacts of IT on growth and productivity. The expectation was that increased investment in IT would naturally lead to increase performance of organization. But despite the massive investments in IT both in the developed and developing economies, the impact of IT on productivity and business performance continued to be questioned(Winter and Taylor, 1999).

The Information Technology is not new. The history of computers began about 2000 years ago, following the birth of the abacus, a wooden rack holding two horizontal wires with beads strung on them. When these beads were moved around, according to programming rules memorized by the user and all regular arithmetic problems were done. Another important invention around the same time was the Astrolabe, used for navigation. Blaise Pascal is usually credited with building the first digital computer in 1624 which added numbers entered with dials. In 1671, Gottfried Wilhelm Von Leibniz started assembling a computer which was completed in 1694. It could add, and, after changing some gadget around, multiply. Leinbniz invented a special stepped gear mechanism for introducing the addend digit, and this still being used. Thomas of Colmar created the first successful mechanical calculator that could add, subtract, multiply and divide. By 1890, a range of improved desktop calculators were available (Shelly et. al, 2004).

Information Technology is the outgrowth of the microelectronics revolution and is one of the advanced and fast growing technology of the world. The modern data processing business dates from about 1963 when International Business Machine (IBM), already a leader in 
mainframe computer systems, introduced system/360, a family of machines that was broadly compatible and which had the facility to use the same operating software. The computer became more central to business operations with the evolution of the minicomputer in the early 1970s. The microprocessor's invention caused immediate and radical changes in the appearance, capability, and availability of computer(Cane, 1992; Shelly et. al, 2004).

Sushil and Agrawal (2003) discuss that organizations are now composed of five major components: IT, organizational structure \& corporate culture, management \& business processes, organization's strategy, individuals and roles. These components are in stable condition, called equilibrium, as long as no significant changes occur in the environment or in any of the components. However, as soon as a significant change occurs, the systems become unstable and it is necessary to adjust some or all of the internal components since all are inter-related. Unstable organizations may be unable to excel or even survive, therefore, organizations need to respond by what it is called critical response activities, which deal not only with long term strategies, but also with the basic daily business activities. Now IT has become a major facilitator of business activities in the world today to make organizations responsive and remain stable (Mandel et. al, 1994).

Various studies have been undertaken to observe the important role IT plays in business organizations. For example in an early empirical study, Boddy and Buchanan and Boddy(1983) Olalla and Fassas(2000) indicate some more reasons for IT introduction in organizations, these are 1) cost savings and improving the accuracy of exchanging information 2) avoiding human mistakes inherent when complex repetitive tasks are used 3) saving money by reducing time and errors 4) integration of several functions 5) improving organization's efficiency and effectiveness by eliminating delay, administrative intermediaries and redundant processing steps and by providing better access and information.

Zee (2002) found in his research that the higher management performance in the organization is achieved through business activities, grouped together in business process and through the organization and allocation of resources to these business processes. He reports that IT is playing an important role in all business processes now. The business performance is attained through well-designed business activities that need to be changed as per requirement of customer and market need. IT now is an important tool for organization change and efficiency, for business process reengineering for effectively supporting all business processes activities and employees. The ensuing discussion elaborates the IT role in increasing business processes activities in detail.

The goal of every information systems, based in any organization is to improve performance on the job and this performance efficiency is only achieved when IT is deployed properly. The slow IT diffusion in developing countries could be attributed to poor infrastructure, language barriers, sociopolitical, cultural and economic risks and conflicts (Chan 2000; Odedra \& Kluizer, 1998).

One reason for the failure of IT projects is absence detailed study of the ecology of information within organizations (Turban, et al, 2006). Ecology is the study of the behavior 
of organisms in their ecological context and Recognition is their interactions with each other and their surroundings. (Turban, et al, 2006). The purpose of ecology of information is recognition the components of surroundings by the opportunities and avoid of its threats to preservation the survival and development of ecology (Turban, et al, 2006).

The research was conducted in 2001 by the Institute of board meeting, 116 companies have been questioned about the use of information technology that the following results were obtained:

- $34 \%$ claimed they are very satisfied.

- $58 \%$ are somewhat satisfied.

- $8 \%$ are not satisfied of they have gained.

- $60 \%$ are unsuccessful in first year of utilization of IT projects in achieving their goals (Turban, et al, 2006).

KPMG Company, Canada branch in 1999 has sent a questionnaire survey and analysis of the reasons for the failure of IT projects to 1450 leading public and private companies in. The purposes of this study are recognition and analyze and the reasons for the failure of correlate projects to information systems that the following results were obtained:

-More than $61 \%$ of the projects have failed

- More than $75 \%$ of them are evaluated more deficient than initial designing and plans.

- More than $50 \%$ of them with a significant margin rejected the initial estimated budget (Turban, et al, 2006).

The Economist in its 2002 report noted that:

Between one-fifth to one-fourth of ICT projects, has evaluated is completely failure. Somewhere from one-third to three-fifths are defeated in some parts, and the remained fraction is evaluated partially successful (Turban, et al, 2006). In this paper, identification and prioritization of effective indicators on the implementation of IT projects in Iranian organizations are accomplished. Software Projects management is the first layer of the software engineering process. This type of management is not called a step or an activity, because it supervises the other project activities in all phases of project development. Thus, the layer name is the most appropriate name for the software projects management. Implementation of IT projects, Requires strategic and reasoning theory and integrated and constant planning and Comprehensive support structure.

\section{Dematel Method}

In the last of 1971, DEMATEL technique primarily for the study of global complex issues and the use of comments and suggestions from experts and scholars in the fields of science, politics, economics and ... Was used. (Asgharpour, MJ, 2006).

\subsection{Advantages of DEMATEL}

- This technique extracts influence relations and mutual impressibility of the elements of the studied graph by utilizing the principles of graph theory. 
- Determined the intensity of these relations into numerical scores.

- Using feedback relationships is the advantages of this method over other methods of decision making.

- It means in the structure of these techniques. Each element can affect the level of all elements, higher and lower levels and in front of each of them takes effect.

- The importance and weight of the model, not only by upstream or downstream factors but also by all the elements of the model or in other words, whole of model are determined. (Asgharpour, MJ, 2006).

In this paper, after studying the literature, the effective Indicators on implementation of IT projects in various organizations are studied. As regards, the present paper is seeks to identification and prioritization of effective indicators on the implementation of IT projects in Iranian organizations, In the second step of obtaining expert panel (Initial Questionnaire), effective Indicators on the implementation of IT projects in Iranian organizations from the identified indicators in different organizations, Screened and identified, afterwards, study of Identified indicators to prioritization mentioned indicators for the implementation of IT projects in Iran are done.

\section{Research Steps}

\subsection{First Step}

After studying literature and interviews with experts using the Delphi method, 10 followed indicators as effective indicators on implementation of IT projects in various organizations were identified:

Table 1. Effective indicators in various organizations

\begin{tabular}{|l|l|}
\hline \multirow{3}{*}{} & 1. Support and commitment of senior management \\
\cline { 2 - 3 } & 2. Systematic and integrated approach to the implementation of IT projects \\
\cline { 2 - 3 } & 3. Resistance to stuffs change \\
\cline { 2 - 3 } & 4. Allocation of financial resources \\
\cline { 2 - 3 } & 5. information infrastructure of Organization \\
\cline { 2 - 3 } & 6. Alignment of IT strategy with organization strategy \\
\cline { 2 - 3 } & 7. Encourage new ideas in order to support of implementation of project \\
\hline & 9. Long-term plans of the organization \\
\hline
\end{tabular}

\subsection{Second Step}

Screening identified indicators from the literature study using binomial test: 
In the hypothesis testing, the lack of effectiveness of indicator in decision-making, from 0 to 50 is considered and effectiveness of indicator in decision-making is from 50 to 100 (greater than 50 ). Thus, the comparison with 0.5 ratio is donning, because the 5 option to 10 option ratio is equivalent to 0.5 . Therefore, whatever the ratio of $5 / 0$ is larger, increases the number of people who are believe in affectivity of indicators.

H0: $(\mathrm{P} \leq 0 / 5)$

$\mathrm{H} 1:(\mathrm{P}>0 / 5)$

The result is an output (Table 2) that from right-side shows obtained indicators, the data of each group, the ratio of observation, the test ratio and Sig. Since all of the variables sig are less than 0.5 , Assumption of equality of success ratio for these variables with 0.5 is rejected.

Table 2. The selected "effective indicators" in various organizations

\begin{tabular}{|c|c|c|c|c|}
\hline Sig & $\begin{array}{c}\text { Test } \\
\text { ratio }\end{array}$ & $\begin{array}{c}\text { observated } \\
\text { ratio }\end{array}$ & $\begin{array}{c}\text { The data of } \\
\text { each group }\end{array}$ & Selected indicators \\
\hline 0.021 & 0.50 & 0.10 & 10 & $\begin{array}{c}\text { Support and commitment of senior } \\
\text { management }\end{array}$ \\
\hline 0.002 & 0.50 & 0.00 & 10 & $\begin{array}{c}\text { Systematic and integrated approach to the } \\
\text { implementation of IT projects }\end{array}$ \\
\hline 0.021 & 0.50 & 0.10 & 10 & Allocation of financial resources \\
\hline 0.039 & 0.50 & 0.20 & 10 & information infrastructure of organization \\
\hline 0.002 & 0.50 & 0.00 & 10 & $\begin{array}{c}\text { Alignment of IT strategy with } \\
\text { organizational strategy }\end{array}$ \\
\hline 0.021 & 0.50 & 0.10 & 10 & Attention to information ecology \\
\hline 0.002 & 0.50 & 0.00 & 10 & Long-term plans of the organization \\
\hline
\end{tabular}

\subsection{Third Step}

distributing the second questionnaire to determine the type and intensity of identified indicators relation from the initial questionnaire.

The second questionnaire to determine the type and intensity of the relations between the main indicators (screened indicators of initial questionnaire) renewed obtaining expert's opinion to study the implementation of IT projects in Iranian organizations, Developed and distributed that by Using Semi metric range also was determined the type and intensity correlation and ultimately was led to the formation of system relation intensity matrix to determine relation intensity of effective indicators by DEMATEL method. In second questionnaire to scrutiny the relations of effective indicators on implementation of IT projects, to study the influence intensity of indicators on each other in pairs (two by two), some questions are used.

\subsection{Fourth Step: Using DEMATEL}

DEMATEL method is used in the following steps: 


\section{Macrothink}

3.4.1 First Step: Identifying System Elements Using Expert Opinion (Delphi Method)

3.4.2 Second Step: Paired comparisons of elements with experts' judgments. To communication of elements with each other seven identified indicators from first index to seventh index in DEMATEL method is a sequence from X1 to X7 are considered.

\begin{tabular}{|c|c|c|c|c|c|c|c|c|}
\hline & $\mathrm{Y}$ & $\mathrm{X} 1$ & $\mathrm{X} 2$ & $\mathrm{X} 3$ & $\mathrm{X} 4$ & $\mathrm{X} 5$ & $\mathrm{X} 6$ & $\mathrm{X} 7$ \\
\hline $\mathrm{Y}$ & & & & & & & & \\
\hline $\mathrm{X} 1$ & & & & & & & & \\
\hline $\mathrm{X} 2$ & & & & & & & & \\
\hline $\mathrm{X} 3$ & & & & & & & & \\
\hline $\mathrm{X} 4$ & & & & & & & & \\
\hline $\mathrm{X} 5$ & & & & & & & & \\
\hline $\mathrm{X} 6$ & & & & & & & & \\
\hline $\mathrm{X} 7$ & & & & & & & & \\
\hline
\end{tabular}

Figure 1. sequence of indicators in DEMATEL Method

3.4.3 Third Step: Accomplishment Group Decision-Making Rule to Consensus for the Relation Between the Elements

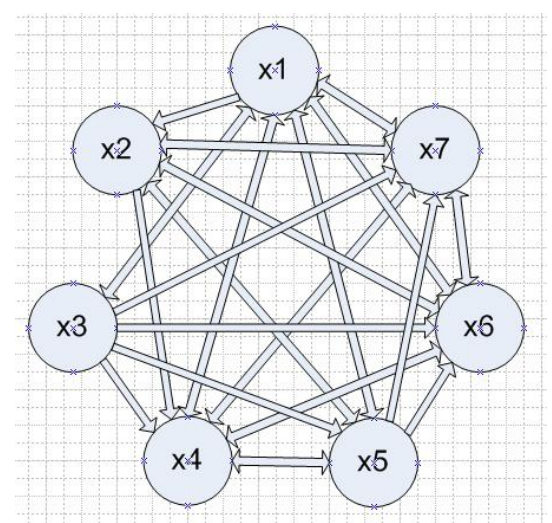

Figure 2. Diagraph of group decision-making to consensus for the relation between the elements

3.4.4 Fourth Step: expert consensus to end relations intensity (zero to 100)

3.4.5 Fifth step: forming the matrix of system relations intensity 


$\begin{array}{rrrrrrr}0 & 75.4630 & 52.6400 & 55.0012 & 60.0000 & 66.5500 & 54.0000 \\ 50.3300 & 0 & 0 & 57.6600 & 51.0000 & 54.0000 & 43.3300 \\ 58.3300 & 73.0000 & 0 & 56.3300 & 0 & 0 & 53.6600 \\ 70.0000 & 0 & 0 & 0 & 70.6600 & 66.6600 & 43.6600 \\ 64.0000 & 56.6600 & 0 & 46.0000 & 0 & 54.0000 & 51.0000 \\ 58.3300 & 55.0000 & 0 & 76.6600 & 0 & 0 & 58.3300 \\ 50.0000 & 56.3300 & 0 & 46.6600 & 0 & 55.0000 & 0\end{array}$

3.4.6 Sixth step: forming the matrix of Relative intensity governing the direct relations

$$
\left(\mathrm{M}=\alpha \cdot{ }^{\wedge} \mathrm{M}\right)
$$

$\begin{array}{rrrrrrr}0 & 0.1802 & 0.1622 & 0.1486 & 0.1531 & 0.1126 & 0.1396 \\ 0.2027 & 0 & 0 & 0.1576 & 0.1892 & 0.1576 & 0.1441 \\ 0.1261 & 0.1486 & 0 & 0.1261 & 0 & 0 & 0.2072 \\ 0.1486 & 0 & 0 & 0 & 0.1892 & 0.1351 & 0.1622 \\ 0.1351 & 0.2027 & 0 & 0.1802 & 0 & 0.1576 & 0.1216 \\ 0.1622 & 0.1396 & 0 & 0.1576 & 0 & 0 & 0.1126 \\ 0.1126 & 0.1802 & 0 & 0.1261 & 0 & 0.1892 & 0\end{array}$

3.4.7 Seventh step: forming the matrix of possible intensity of all direct and indirect relations.

$\begin{array}{rlllrll}0.4667 & 0.4968 & 0.4359 & 0.3314 & 0.6047 & 0.0781 & 0.4489 \\ 0.4603 & 0.0781 & 0.0606 & 0.3335 & 0.4728 & 0.0840 & 0.4675 \\ 0.4050 & 0.4813 & 0.2281 & 0.5342 & 5141 & 0.7080 & 0.4813 \\ 0.2281 & 0.4335 & 0.5141 & 0.4590 & 0.2281 & 0.3252 & 0.3335 \\ 0.3314 & 0.4109 & 0.3252 & 0.4024 & 0.5101 & 0.4739 & 0.5486 \\ 0.4044 & 0.4072 & 0.1954 & 0.4603 & 0.0605 & 0.3314 & 0.1954 \\ 0.1954 & 0.4727 & 0.3443 & 0.1954 & 0.0715 & 0.5483 & 0.3252\end{array}$

The matrix of Relative intensity of direct and indirect relations

3.4.8 Eighth step: forming the matrix of Relative intensity of indirect relations

$\begin{array}{lllllll}0.4739 & 0.4317 & 0.0726 & 0.4356 & 0.2737 & 0.4245 & 0.3996 \\ 0.3315 & 0.3335 & 0.0715 & 0.3098 & 0.2092 & 0.3241 & 0.2946 \\ 0.3044 & 0.2812 & 0.0708 & 0.2957 & 0.2252 & 0.3252 & 0.2681 \\ 0.3209 & 0.3563 & 0.0781 & 0.3299 & 0.1933 & 0.3167 & 0.2983 \\ 0.3594 & 0.3540 & 0.0840 & 0.3596 & 0.2522 & 0.3654 & 0.3266 \\ 0.3117 & 0.2858 & 0.0705 & 0.3014 & 0.2281 & 0.3314 & 0.2714 \\ 0.2693 & 0.2512 & 0.0605 & 0.2563 & 0.1954 & 0.2673 & 0.2512\end{array}$

The matrix of Relative intensity of indirect relations 


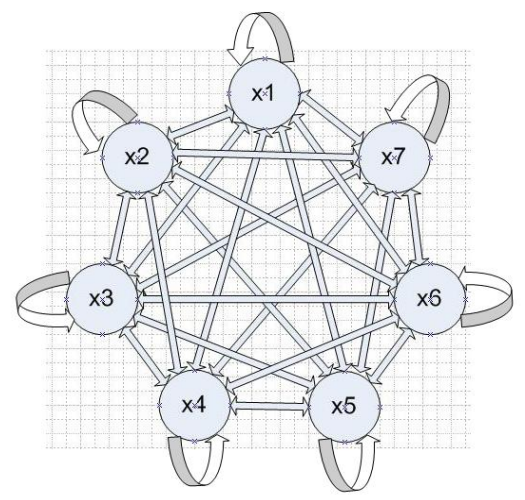

Figure 3. Diagraph of indirect relationship with the relative intensity

3.4.9 Ninth step: Determination of the hierarchy of elements

Table 3. hierarchy of elements

\begin{tabular}{|c|c|c|c|c|c|c|c|}
\hline $\begin{array}{c}\text { Sequence } \\
\text { of } \\
\text { elements } \\
\text { location }\end{array}$ & $\begin{array}{c}\text { Based on } \\
\text { The } \\
\text { maximum } \\
\text { total row } \\
(\mathrm{R})\end{array}$ & $\begin{array}{c}\text { Sequence } \\
\text { of } \\
\text { elements } \\
\text { location }\end{array}$ & $\begin{array}{c}\text { Based on } \\
\text { The } \\
\text { maximum } \\
\text { total } \\
\text { column (J) }\end{array}$ & $\begin{array}{c}\text { Sequence } \\
\text { of } \\
\text { elements } \\
\text { location }\end{array}$ & $\begin{array}{c}\text { Based on } \\
(\mathrm{R}+\mathrm{J})\end{array}$ & $\begin{array}{c}\text { Sequence } \\
\text { of } \\
\text { elements } \\
\text { location }\end{array}$ & $\begin{array}{c}\text { Based on } \\
(\mathrm{R}-\mathrm{J})\end{array}$ \\
\hline $\mathrm{X} 1$ & $3 / 5116$ & $\mathrm{X} 1$ & $3 / 3170$ & $\mathrm{X} 1$ & $6 / 8286$ & $\mathrm{X} 3$ & $1 / 7672$ \\
$\mathrm{X} 5$ & $2 / 8805$ & $\mathrm{X} 2$ & $3 / 2441$ & $\mathrm{X} 2$ & $5 / 8087$ & $\mathrm{X} 5$ & $0 / 8169$ \\
$\mathrm{X} 4$ & $2 / 5646$ & $\mathrm{X} 4$ & $3 / 1757$ & $\mathrm{X} 4$ & $5 / 7403$ & $\mathrm{X} 1$ & $0 / 1946$ \\
$\mathrm{X} 2$ & $2 / 5633$ & $\mathrm{X} 6$ & $3 / 1474$ & $\mathrm{X} 6$ & $5 / 6233$ & $\mathrm{X} 4$ & $-0 / 6111$ \\
$\mathrm{X} 6$ & $2 / 4759$ & $\mathrm{X} 7$ & $2 / 9295$ & $\mathrm{X} 7$ & $5 / 0437$ & $\mathrm{X} 6$ & $-/ 6715$ \\
$\mathrm{X} 3$ & $2 / 4283$ & $\mathrm{X} 5$ & $2 / 0636$ & $\mathrm{X} 5$ & $4 / 9441$ & $\mathrm{X} 2$ & $-0 / 6808$ \\
$\mathrm{X} 7$ & $2 / 1142$ & $\mathrm{X} 3$ & $0 / 6611$ & $\mathrm{X} 3$ & $3 / 0894$ & $\mathrm{X} 7$ & $-0 / 8153$ \\
\hline
\end{tabular}

Based on this research, 7 indicators identified as key effective indicators on implementation of information technology project in Iranian organizations, have identified; Then by DEMATEL method effectiveness prioritization of each of these indicators have been obtained.

\section{Conclusions}

After studying literature and Extraction effective factors on implementation of IT projects in various organizations, Statistical analysis showed the 7 following indicators (Table 4), have the most influential on the implementation of IT projects:

Table 4. The most Influential indicators

\begin{tabular}{|l|}
\hline Support and commitment of senior management \\
\hline Systematic and integrated approach to the implementation of IT projects \\
\hline Allocation of financial resources \\
\hline information infrastructure of organization \\
\hline
\end{tabular}




\begin{tabular}{|l|}
\hline Alignment of IT strategy with organizational strategy \\
\hline Attention to information ecology \\
\hline Long-term plans of the organization \\
\hline
\end{tabular}

In continue by DEMATEL group decision-making method, prioritization of 7 mentioned factors in Table 5, after distribution of second questionnaire was done.

Table 5. Prioritization of effective Indicators

\begin{tabular}{|c|c|}
\hline First Priority & Allocation of financial resources \\
\hline Second Priority & Alignment of IT strategy with organizational strategy \\
\hline Third Priority & Support and commitment of senior management \\
\hline Fourth Priority & information infrastructure of organization \\
\hline Fifth Priority & Attention to information ecology \\
\hline Sixth Priority & Systematic and integrated approach to the implementation of IT projects \\
\hline Seventh Priority & . Long-term plans of the organization \\
\hline
\end{tabular}

\section{References}

Asgharpour, Mohammad Javad. (2006). "Multi criteria decision making”, University of tehran publication, pp 191-210.

Buchanan, D. A., \& Boddy, D. (1983). "Organizations in the Computer Age", Gower, Farnborough.

Cane, Allen. (1992). "Information Technology and Competitive Advantage: Lesson from the Developed Countries”. World Development, 20(12), 1721-1736. http://dx.doi.org/10.1016/0305-750X(92)90087-C

Cash, J. I, McFarlan, F. W., \& McKinney. J. L. (1983). “Corporate Information System Management: Text \& cases", Irwin Homewood. IL.

Chan Stephen L. (2000). "Information Technology in Business process". Business Process Management Journal, 6(3), 224-237. http://dx.doi.org/10.1108/14637150010325444

Gupta Uma G. (2000). "Information Systems: Success in the 21st Century", Prentice Hall International U.S.A. pp. 17, 360-372.

Huber, G. (2004). The Necessary nature of future firms: Attributes of survivors in a changing word. San Francisco: Sage Publications.

Kendall, \& Kendall. (2000). "Systems Analysis \& Design”, Prentice Hall International Inc. New Jersey, U.S.A. pp 134.

Laudon, Kenneth C., \& Laudon, Jane P. (1998). "Management Information Systems," Fifth edition, Prentice Hall, Inc. New Jersey. pp. 189,334.

Long Larry, \& Long Nancy. (1999). “Computers”, Prentice Hall Inc. U.S.A.

Mandel, M. J. (1994). “The information revolution”, Special report, Business week, June 13, 
1994.

Mehta Kamlesh T., \& Shah Vivek. (1998). "Workforce, Information Technology and global unemployment”. Industrial Management \& Data Systems, 98(5), 228.

Motiwalla, L., \& A. Hashemi. (2003). "web-Enabling for Competitive Advantage: A Case Study of Himalayan Adventures.

Odedra, M., \& Kluizer, S. (1998). "Bibliography for Information Technology in Developing Counties,” Information Technology for Development. pp. 297-356.

Olalla, Marta Fossas. (2000). "IT in business process reengineering". International Advances in Economic research”, 6(3), 581-590. http://dx.doi.org/10.1007/BF02294975

Oliner, S. D., \& Sichel, D.E. (2000). "The resurgence of growth in the late 1990s: Is Information Technology the story. The journal of Economic perspectives, 14(4), 3-22. http://dx.doi.org/10.1257/jep.14.4.3

Poku K., \& Vlosky R. P. (2002). "A model of the impact of corporate culture on Information Technology adoption", Working paper no 57, School of Renewable Natural resources, Louisiana State University Agriculture Centre, Baton Rough, LA.

Reynolds George W. (1995). "Information Systems for Managers", 3rd edition, West Publishing Company. U.S.A, pp. 2-23, 65-138,186-277.

Robey. D. (1977). "Computers and Management Structure: Some Empirical findings Reexamined”. Human Relations, 30(11), 963-76. http://dx.doi.org/10.1177/001872677703001101

Shelly G. B, T. J. Cashman, \& M. E. Verment. (2004). "Discovering Computers:A gateway to information Web Enhanced", Thomson Course Technology Boston, U.K.

Sushil, Aleem A., \& Agrawal V.K. (2003). "The contribution of IT to critical response activities in business transformation”, working paper, Indian Institute of Technology, Dehli, India.

Turban, E, et al. (2006). Electronic commerce.Upper saddle River, NJ: Prentice Hall.

Whisler, T. L. (1970). "The impact of Computers on Organizations", Praeger Publishers, New York. NY.

William, B. K., \& Sawyar, S. C. (2005). "Using Information Technology", 6th edition, McGra- Hill Publishing Co. U.S.A, pp 3-4,147, 446-457.

Winter, S., \& Taylor, S. L. (1999). The Role of Information Technology in the Transformation of Work. in J. FULK and G. DESANCTIS (eds.). Shaping the Organization Form, Thousand Oaks, California, Sage Publications: 101-128.

Zee, Han, V. D. (2002). "Measuring the value of Information Technology", IRM press, U.S.A, pp 7, 47-48, 64, 67-70, 82, 86. 